\title{
Avaliação do desempenho dos reagentes do tempo de tromboplastina parcial ativada utilizados para detectar 0 anticoagulante lúpico
}

\author{
Assessment of the performance of reagents of activated partial thromboplastin time used to detect the lupus \\ anticoagulant
}

Fernanda Chiuso'; Iracema Carvalho Ferrari²; Izolete Aparecida Thomazini Santos ${ }^{3}$

\begin{abstract}
unitermos
Anticoagulante lúpico

Tempo de tromboplastina parcial

ativada (TTPA)

Teste do TTPA

\section{resumo}

Introdução: $\mathrm{O}$ anticoagulante lúpico é uma imunoglobulina pertencente à família dos anticorpos antifosfolípides. A sua ação in vitro é interferir nos testes de coagulação dependentes de fosfolípides. O tempo de tromboplastina parcial ativada (TTPA) é um teste utilizado como screening na pesquisa do anticoagulante lúpico. Os reagentes utilizados neste teste apresentam grandes variações quanto à sensibilidade. Objetivo: Avaliar o desempenho dos reagentes do TTPA e detectar a presença do anticoagulante lúpico através de diferentes testes da coagulação. Material e método: A pesquisa do anticoagulante lúpico foi realizada em 50 amostras plasmáticas de pacientes do sexo feminino através dos testes do TTPA, do tempo de coagulação do caulim (TCC), do tempo de tromboplastina parcial ativada diluída (TTPAd) e do tempo do veneno da víbora de Russel diluído (TVVRd). Três cefalinas comerciais foram avaliadas pelos testes do TTPA e do TTPAd. Na comparação entre os reagentes estudados foi aplicado o cálculo do intervalo de confiança (95\%). Resultados: Os três reagentes avaliados apresentaram boa concordância e os métodos utilizados responderam bem à pesquisa do anticoagulante lúpico. Discussão e Conclusão: As três cefalinas comerciais avaliadas podem ser utilizadas na rotina laboratorial para a pesquisa do anticoagulante lúpico.
\end{abstract}

abstract

Introduction: The lupus anticoagulant is an immunoglobin which belongs to the antiphospholid antibodies family. Its in vitro function is to interfere with coagulation tests that are dependent on phospholipids. The activated partial thromboplastin time (APTT) is a test used as screening on lupus anticoagulant research. Reagents used in this test demonstrate wide sensitivity ranges. Objective: To assess the performance of APTT reagents and detect the presence of lupus anticoagulant through various coagulation tests. Material and method: The lupus anticoagulant research was performed in plasma from 50 female patients through APTT tests, Kaolin clotting time; dilute activated partial thromboplastin time (dAPTT) and dilute Russell's viper venom time. Three commercial cephalins were assessed through APTT and dAPTT tests. The confidence interval (95\%) was used in the comparison among studied reagents. Results: The three assessed reagents presented good accordance and the used methods answered well to the lupus anticoagulant research. Discussion and Conclusion: The three assessed commercial cephalins can be used in laboratorial routine for the lupus anticoagulant research. key words

Lupus anticoagulant

Activated partial thrombo-

plastin time (APTT)

APTT test

\footnotetext{
1. Farmacêutica-bioquímica; mestra em Pesquisa e Desenvolvimento: Biotecnologia Médica pela Faculdade de Medicina de Botucatu da Universidade Estadual Paulista (FMB/UNESP). 2. Bióloga; mestra em Patologia pela FMB/UNESP.

3. Bióloga; doutora em Doenças Tropicais; docente do curso de pós-graduação em Pesquisa e Desenvolvimento: Biotecnologia Médica da FMB/UNESP.

Trabalho realizado no Laboratório de Hemostasia da Divisão Hemocentro, FMB/UNESP.

Dissertação apresentada ao curso de pós-graduação em Pesquisa e Desenvolvimento: Biotecnologia Médica para obtenção do título de mestre da FMB/UNESP.
} 


\section{Introdução}

Os anticorpos antifosfolípides (AAF) representam uma grande família de imunoglobulinas com afinidades variáveis por fosfolípides ( $\mathrm{PL}^{-}$), por complexos de proteínas e fosfolípides, ou através de ambos ${ }^{(24)}$. A beta-2-glicoproteína $\mathrm{I}\left(\beta_{2} \mathrm{GPI}\right)^{(15)} \mathrm{e}$ a protrombina ${ }^{(6)}$ são os principais alvos antigênicos dos AAF. Existem dois tipos de anticorpos antifosfolípides: anticorpo anticardiolipina ( $\mathrm{aCL}$ ) e anticoagulante lúpico $(\mathrm{AL})^{(5)}$. Tanto o AL quanto o aCL podem estar associados a diferentes manifestações clínicas, como trombose arterial e venosa $^{(21)}$, complicações obstétricas ${ }^{(20)}$, trombocitopenia ${ }^{(23)}$, síndromes renais ${ }^{(30)}$ e manifestações cutâneas ${ }^{(28)}$.

O AL corresponde a um grupo heterogêneo de imunoglobulinas dos isotipos $\lg \mathrm{G}$, IgM ou à mistura de ambas, que agem interferindo in vitro nos testes de coagulação dependentes de fosfolípides, levando a um prolongamento dos testes de protrombina (TP), do tempo de tromboplastina parcial ativada (TTPA) e do tempo do veneno da víbora de Russel diluído (TVVRd) ${ }^{(31,37)}$.

Alguns autores demonstram que os testes de coagulação utilizados rotineiramente, aos quais os fosfolípides são adicionados no sistema teste, especialmente o teste do TTPA, são pouco sensíveis para detectar a presença do $A L^{(19,32)}$. No entanto, uma simples diluição do reagente do TTPA ou de fosfolípides tem sido proposta por aumentar a sensibilidade do teste para o $\mathrm{AL}^{(1)}$. O tempo de coagulação do caulim (TCC) é um bom teste de screening para o $\mathrm{AL}^{(25)}$ por não lhe serem adicionados fosfolípides ${ }^{(12)}$. O TVVRd é sensível para o AL ${ }^{(38)}$, porém a sua sensibilidade depende da composição do reagente de fosfolípides utilizado no teste ${ }^{(22)}$.

Os anticorpos direcionados contra a protrombina e contra a $\beta_{2}$ GPI parecem ser os mais especificamente envolvidos na síndrome do anticorpo antifosfolípide ${ }^{(35)}$. Os anticorpos antiprotrombina inibem a ativação do fator $X$ e da protrombina, enquanto os anticardiolipina, isto é, os anti- $\beta_{2} \mathrm{GPI}$, inibem a ativação da protrombina mas não o fazem com a ativação do fator $X^{(17)}$. Desta forma, o teste do $\operatorname{TCC}^{(6,17)}$, que avalia a geração de fator $X a$, e a ativação da protrombina ${ }^{(17)}$ têm maior sensibilidade na detecção dos anticorpos direcionados contra a protrombina. Entretanto, o teste do TVVRd ${ }^{(14,16,18)}$, que avalia a conversão de protrombina em trombina ${ }^{(17)}$, tem maior sensibilidade em detectar os anticorpos direcionados contra a $\beta_{2} \mathrm{GPI}$. Arnout et al., em 1998 ${ }^{(4)}$, demonstraram que o teste do TTPA tem baixa sensibilidade para detectar anticorpos direcionados contra a $\beta_{2} \mathrm{GPI}$, mas a sensibilidade é maior para detectar anticorpos direcionados contra a protrombina.
De qualquer modo, o TTPA ainda é o teste mais comumente usado para o screening do AL. Vários estudos mono e multicêntricos têm documentado grandes variações na sensibilidade dos reagentes do TTPA para $\circ \mathrm{AL}^{(8,9,26,36)}$. Estas diferenças aparecem devido à quantidade, natureza e às propriedades físicas dos fosfolípides usados como substitutos de plaquetas ${ }^{(36)}$.

\section{Objetivo}

O objetivo do presente estudo foi comparar o desempenho dos reagentes do TTPA utilizados para detectar o AL e efetuar a pesquisa do mesmo através de diferentes testes da coagulação.

\section{Material e método}

Foram estudadas 50 amostras de plasmas estocados de pacientes do sexo feminino com idade variando de 18 a 45 anos, média de 30,1 anos, que foram encaminhadas ao laboratório de hemostasia para investigação de eventos tromboembólicos e/ou abortos recorrentes. O trabalho foi realizado após aprovação do Comitê de Ética e Pesquisa da Faculdade de Medicina de Botucatu da Universidade Estadual Paulista (FMB/UNESP).

O sangue periférico foi coletado em tubos de polipropileno contendo citrato de sódio a 3,8\%, na razão de nove partes de sangue para uma de anticoagulante. Os tubos foram centrifugados duas vezes a 2.500rpm por 15 minutos para a obtenção do plasma pobre em plaquetas (PPP), o qual foi aliquotado e congelado a $-20^{\circ} \mathrm{C}$ até a realização dos testes ${ }^{(10)}$.

O pool de plasmas normais (PN) utilizado nos testes foi constituído do plasma de vinte indivíduos voluntários, sendo dez homens e dez mulheres, que apresentaram resultados negativos para o AL quando testados com TTPA, TCC e TVVRd.

\section{Estudos da coagulação}

Os testes foram realizados manualmente e em duplicatas no plasma das 50 pacientes, no PN e na mistura do plasma do paciente (PP) com o PN na proporção 1:1. Quatro testes foram utilizados para pesquisar o AL.

\section{Tempo de tromboplastina parcial ativada}

O teste foi realizado diante de três diferentes reagentes comerciais (Tabela 1). O procedimento foi realizado de acordo com as instruções dos fabricantes. A mistura (1:1) 
Tabela 1

\section{Características dos reagentes do TTPA}

\begin{tabular}{cccccc}
\hline n & Reagente & Fabricante & Fosfolípides & Ativador & Tempo de incubação (minutos) \\
A & PTT-LA & Diagnostica Stago & Cérebro de coelho & Sílica & Três \\
B & STA $^{\circledR}$-PTTA5 & Diagnostica Stago & Cérebro de coelho & Sílica & Três \\
C & PLATELIN $^{\circledR L S}$ & Biomérieux & Porco e galinha & Sílica & Cinco \\
\hline
\end{tabular}

do PP com o PN foi realizada e o teste, repetido no tempo zero e após 2 horas de incubação a $37^{\circ} \mathrm{C}$. Recomenda-se a realização do teste da mistura quando os resultados se apresentam alterados. Em nosso estudo, o teste foi realizado em todas as amostras.

Os resultados do teste TTPA foram considerados anormais quando a razão PP/PN foi acima de $1,2^{(13)}$.

\section{Tempo de tromboplastina parcial ativada diluída}

O teste foi realizado com os reagentes comerciais (Tabela 1). O procedimento foi efetuado conforme descrito por Violi et al. ${ }^{(40)}$, segundo os quais foram realizadas diluições (1:5 e 1:80) do reagente do TTPA em tampão Veronal de Owren's ( $\mathrm{pH}=7,35$ ) e o ativador de contato, caulim, foi diluído $1: 15^{(13)}$.

Para cada reagente utilizado foram feitas as determinações dos valores de referência normais. Para isto foram avaliados 20 indivíduos voluntários, sendo dez homens e dez mulheres, todos negativos para o AL quando testados com TTPA, TCC e TVVRd. O valor de referência normal foi determinado pela média mais um desvio-padrão. $O$ resultado foi considerado anormal quando a diferença entre as diluições 1:80 e 1:5 foi acima de 26 segundos com o A, acima de 20 segundos com o $B$ e acima de 15 segundos com o $C$.

\section{Tempo de coagulação do caulim}

No teste do TCC utilizou-se o ativador de contato kaolin $\left(\right.$ Sigma $\left.^{\circledR}\right)$ diluído a $2 \%{ }^{(12)}$.

Considerou-se o resultado anormal quando a razão entre PP e PN foi maior que 1. Então foi realizada a mistura do PP com o PN na razão 1:1 ${ }^{(33)}$ e o teste foi repetido. Considerouse o resultado negativo quando a razão da mistura (PP + $\mathrm{PN}$ )/PN foi de até 1,09; inconclusivo se a razão foi de 1,1 a 1,19 ; e positivo se for $\geq 1,2^{(12)}$.

\section{Tempo do veneno da víbora de Russel diluído}

Este teste foi avaliado pelos reagentes comerciais LA1 Screening Reagent e LA2 Confirmation Reagent (Dade Behring), segundo orientações do fabricante.
Se a razão PP/PN foi maior que $1,2^{(22)}$ com o LA1 Screening Reagent, o teste foi realizado com o LA2 Confirmation Reagent. Em nosso estudo, todas as amostras foram testadas com o LA2 Confirmation Reagent. Considerou-se o resultado anormal quando a razão LA1/LA2 foi maior que 1,3. Em seguida, os testes foram repetidos pela mistura volume/volume do PP com o PN.

\section{Análise estatística}

Para comparar o desempenho dos reagentes de TTPA diante das amostras de plasmas testadas, foi aplicado o cálculo do intervalo de confiança (95\%) para determinar a proporção de concordância ${ }^{(29)}$.

\section{Resultados}

O resultado dos testes realizados entre as duplicatas não demonstrou diferença significativa.

A Tabela 2 demonstra os resultados do teste do TTPA. Os resultados da análise estatística realizada no teste do TTPA estão expressos na Tabela 3.

O teste do TTPA da mistura (PP $+\mathrm{PN})$, no tempo zero e após duas horas de incubação a $37^{\circ} \mathrm{C}$, apresentou $8 \%$ de positividade perante os três reagentes avaliados (Figura 1).

A análise estatística realizada, comparando os resultados do teste do TTPA da mistura (PP + PN) dos três reagentes, revelou uma concordância de $100 \%$.

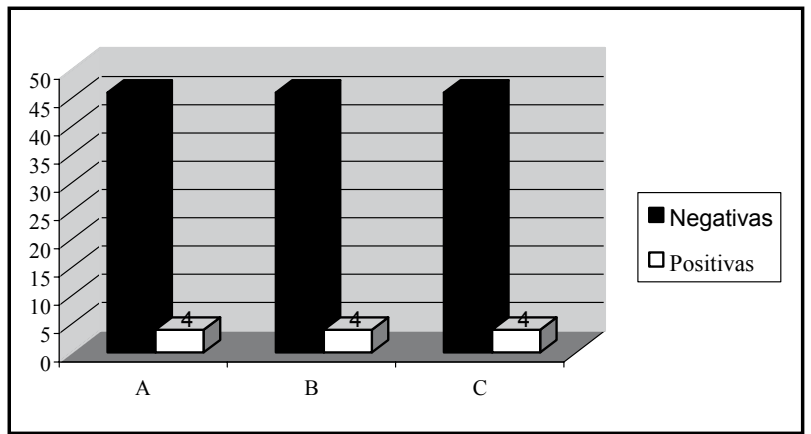

Figura 1 - Resultados obtidos com o teste do TTPA da mistura de plasmas (PP + $P N)$ realizada com $A, B$ e $C$ 


\section{Tabela 2 Resultados dos testes do ITPA e do ITPAd}

Reagentes

A

B

C
Amostras com resultados acima do valor de referência normal TTPA TTPAd
$12(24 \%)$
$12(24 \%)$
$4(8 \%)$

$20(40 \%)$

$17(34 \%)$

$13(26 \%)$

\section{Tabela 3 Resultados do cálculo do intervalo de confiança (95\%) nos testes do TTPA e do TIPAd}

\begin{tabular}{ccccc}
\hline Reagentes & \multicolumn{2}{c}{$\begin{array}{c}\text { Proporção de concordância (\%) } \\
\text { TTPAd }\end{array}$} & \multicolumn{2}{c}{ Amostras Concordantes $(n=50)$} \\
TTPA & 66 a 90 & 46 & TTPAd \\
A x B & 84 a 100 & 57 a 83 & 42 & 39 \\
B x C & 74 a 94 & 60 a 84 & 42 & 35 \\
\hline
\end{tabular}

Os resultados do teste TTPAd estão expressos na Tabela 2. A Tabela 3 demonstra os resultados da análise estatística realizada no teste do TTPAd.

Após a adição de plasma normal, a positividade no teste do TTPAd foi de $8 \%$, perante os três reagentes avaliados (Figura 2).

A análise estatística realizada, comparando os resultados do teste do TTPAd da mistura (PP + PN) dos três reagentes, revelou uma concordância de $100 \%$.

Quando realizamos o teste do TCC, cinco amostras (10\%) apresentaram resultados positivos, enquanto outras duas (4\%) apresentaram resultados inconclusivos.

Quando realizamos o teste do TVVRd, quatro amostras (8\%) apresentaram resultados positivos, que se repetiram para os testes do TCC, TTPA e TTPAd.

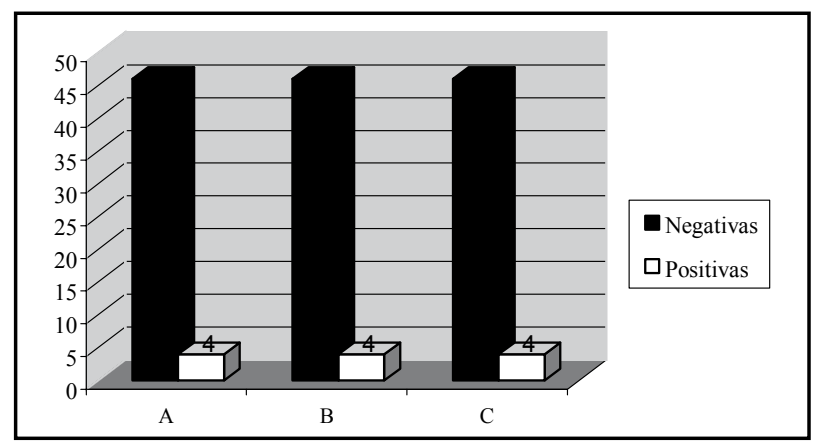

Figura 2 - Resultados obtidos com o teste do TTPAd da mistura de plasmas (PP + $P N)$ realizada com $A, B$ e C

\section{Discussão e conclusão}

Devido à dificuldade de um procedimento padrão de referência para o diagnóstico do AL, vários testes são realizados para este fim $^{(3,12,34)}$. O TTPA ainda é o teste mais comumente utilizado para o screening do $\mathrm{AL}$, porém os seus reagentes diferem na sensibilidade e na resposta ao AL. Diante dos nossos resultados, podemos observar que os reagentes que apresentam fosfolípides de cérebro de coelho têm maior resposta de positividade diante do reagente que é composto de fosfolípides de porco e galinha, visto que a fonte ativadora de superfície é a mesma para os três reagentes, no caso a sílica. A análise estatística não revelou diferença significante entre os resultados dos três reagentes avaliados. Denis-Magdelaine et al. ${ }^{(11)}$ avaliaram 16 cefalinas comerciais e observaram que os reagentes compostos por fosfolípides de cérebro animal e que apresentam a sílica como superfície ativadora são mais sensiveis para a pesquisa do AL, enquanto reagentes compostos por fosfolípides humanos ou de soja, e que apresentam como ativador de contato a celite ou o caulim, parecem ser menos sensiveis para detectá-lo. Ames et al., em 2001(2), demonstraram que os reagentes compostos por fosfolípides de soja são insensíveis para o AL.

A sensibilidade do teste do TTPA para o AL varia de acordo com os diferentes reagentes utilizados ${ }^{(39)}$. No entanto, Alving et al.(1) demonstraram que uma simples diluição do reagente do TTPA ou de fosfolípides aumenta a sensibilidade do teste para o AL. As amostras (8\%) que foram positivas no teste do TTPAd também apresentaram 
resultados positivos nos demais testes utilizados. A análise estatística realizada, comparando os resultados do teste do TTPAd não demonstrou diferença significante. Desta maneira, as três cefalinas demonstraram boa resposta na pesquisa do AL. Em nosso estudo, o TTPAd demonstrou ser um bom teste de screening para o AL. Entretanto, Blanco et al. ${ }^{(7)}$ ressaltam que o uso de fosfolípides diluídos pode diminuir a sensibilidade do teste.

O teste do TCC é muito utilizado para identificar o $A L$, pois não Ihe são adicionados fosfolípides. Em nosso estudo, dos $10 \%$ de resultados positivos no teste do TCC, uma das amostras (2\%) apresentou resultados negativos nos demais testes utilizados, inclusive no TVVRd. O teste do TCC dessa amostra e da mistura (PP $+\mathrm{PN})$ foi repetido e o resultado permaneceu positivo, o que sugere a presença de um anticorpo direcionado contra a protrombina ${ }^{(6,17)}$. As amostras que apresentaram resultados inconclusivos (4\%) foram negativas para os demais testes. Segundo a literatura, os testes que apresentarem resultados inconclusivos e positivos para o $\mathrm{AL}$ devem ser repetidos, com uma nova amostra, após seis semanas ${ }^{(35)}$.
O teste do TVVRd é realizado por um reagente de screening e um reagente confirmatório que contém elevada concentração de fosfolípides que neutralizam o efeito anticoagulante do $\mathrm{AL}^{(22,27)}$. No teste do TVVRd, quatro amostras (8\%) apresentaram resultados positivos, as quais também os apresentaram nos demais testes avaliados, inclusive no teste do TCC, o que sugere a presença de um anticorpo direcionado contra a protrombina ${ }^{(6,17)}$ e contra a $\beta_{2} \mathrm{GPI}^{(14,16)}$. Assim, nosso estudo demonstra que os testes do TCC e do TVVRd são essenciais na pesquisa do $\mathrm{AL}$, já que detectam anticorpos direcionados contra diferentes proteínas.

Na rotina da investigação laboratorial, uma variedade de testes tem sido introduzida para detectar e confirmar o $\mathrm{AL}$, porém a heterogeneidade deste pode, talvez, explicar a necessidade de um procedimento de referência habitual para a sua detecção. $\mathrm{O}$ teste do TTPA é freqüentemente utilizado como screening para a pesquisa do AL. Entretanto,163 a escolha do reagente utilizado no teste é muito importante devido às diferenças de sensibilidade demonstradas em diversas pesquisas. Em nosso estudo, concluímos que as três cefalinas comerciais avaliadas podem ser utilizadas na rotina laboratorial para a pesquisa do anticoagulante lúpico.

\section{Referências}

I.ALVING, B. M. et al.The dilute phospholipid APTT:a sensitive assay for verification of lupus anticoagulants. Thromb Haemost, v. 54, n. 3, p. 709-12, 1985

2. AMES, P. R. J. et al. Improved confirmation of weak lupus anticoagulants by employing sensitive and insensitive reagents to the lupus anticoagulant. Blood Coag Fibrinolysis, v. I2, n. 7, p. 563-7, 200 I.

3. ARNOUT, J. et al. A new lupus anticoagulant neutralization test based on platelet derived vesicles. Br J Haematol, v. 80, n. 3, p. 34I-6, 1992

4.ARNOUT,..et al.Monoclonal antibodies against beta-2-glycoprotein I: use as reference material for lupus anticoagulant tests. Thromb Haemost, v. 79, n. 5, p. 955-8, 1998.

5. BARBUI,T:; GALLI, M. Gli inibitori patologici della coagulazione: meccanismo degli anticorpi antifosfolipidi e loro rilevanza clinica. Transfus Sangue, v. 42, n. I, 1997. Disponível em: <http://www.inmedi.it/simti/trast_sangue/gen-teb9//I -9/art2.htm>. Acesso em: 29 ago 2001 .

6. BEVERS, E. M. et al. Lupus anticoagulant lgG's (LA) are not directed to phospholipids only, but to a complex of lipidbound human prothrombin. Thromb Haemost, v. 66, n. 6, p. 629-32, 1991.

7. BLANCO, A. N. et al. Behaviour of diluted activated partial thromboplastin time in pregnant women with a lupus anticoagulant. Am J Clin Pathol, v. I00, n. 2, p. 99- I02, 1993.

8. BRANDT,J.T. et al.The sensitivity of different coagulation reagents to the presence of lupus anticoagulants. Arch Pathol Lab Med, v. II I, n. 2, p. 120-4, 1987.

9. BRANDT,J.T. et al. Effect of lupus anticoagulants on the activated partial thromboplastin time. Arch Pathol Lab Med, v. I I5, n. 2, p. 109-14, 1991.

I0. BRANDT, J.T. et al. Criteria for diagnosis of lupus anticoagulants: an update. Thromb Haemost, v. 74, n. 4, p. I I 85-90, 1995.

I I. DENIS-MAGDELAINE, A.; FLAHAULT, A.; VERDY, E. Sensitivity of sixteen APTT reagents for the presence of lupus anticoagulants. Haemostasis, v. 25, n. 3, p. 98- I05, 1995.

I2. EXNER,T.; RICHARD, K.A.; KRONENBERG, H.A sensitivity test demonstrating lupus anticoagulant and its behavioral. $\mathrm{Br}$ J Haematol, v. 40, n. I, p. I43-5 I, 1978.

I 3. FERRO, D. et al. Methods for detecting lupus anticoagulants and their relation to thrombosis and miscarriage in patients with systemic lupus erythematosus.) Clin Pathol, v. 45, n. 4, p. 332-8, 1992.

14. GALLI, M.; BEVERS, E. M. Beta 2-glycoprotein I for biding of anticardiolipin antibodies to cardiolipin. Lancet, v. 336, n. 8720, p. 1952-3, 1990.

15. GALLI, M. et al. Anticardiolipin antibodies (ACA) directed not to cardiolipin but to a plasma protein cofactor. Lancet, v. 335, n. 8705, p. 1544-7, 1990.

I6. GALLI, M.et al. Kaolin clotting time and dilute Russell's viper venom time distinguish between prothrombin-dependent and beta 2-glycoprotein l:dependent antiphospholipid antibodies. Blood, v. 86, n. 2, p. 617-23, 1995 
17. GALLI, M.; BARBUI, T. Antiprothrombin antibodies: detection and clinical significance in the antiphospholipid syndrome. Blood, v. 93, n. 7, p. 2149-57, 1999.

18. GALLI, M. et al. The risk of thrombosis in patients with lupus anticoagulant is predicted by their specific coagulation profile. Thromb Haemost, v. 8I, n. 5, p. 695-700, 1999.

19. GASTINEAU, D. A. et al. Lupus anticoagulant: an analysis of the clinical and laboratory features of 219 cases. Am J Hematol, v. 19, n. 3, p. 265-75, 1985.

20. GEIS,W:; BRANCH,W. Obstetric implications of antiphospholipid antibodies: pregnancy loss and other complications. Clin Obstet Gynecol, v. 44, n. I, p. 2- I 0, 2001.

2।. GINSBERG, J. S. et al. Antiphospholipid antibodies and venous thromboembolism. Blood, v. 86, n. I0, p. 3685-9I, 1995.

22. GREAVES, M. et al. Guidelines on the investigation and management of the antiphospholipid syndrome. $\mathrm{Br} J$ Haematol, v. 109, n. 4, p. 704-15, 2000.

23. HARRIS, E. N. et al. Anticardiolipin antibodies: detection by radioimmunoassay and association with thrombosis in systemic lupus erythematosus. Lancet, v. 2, n. 836 I, p. 12 I I-4, 1983.

24. LEVINE, J. S.; BRANCH, D.W.; RAUCH, J. Medical progress: the antiphospholipid syndrome. N Eng J Med, v. 346, n. 10, p. 752-63, 2002.

25. LUBBE, W. F.; LIGGINS, G. C. Role of lupus anticoagulant and autoimmunity in recurrent pregnancy loss. Semin Reprod Endocrinol, v. 6, p. I81-90, 1988.

26. MANNUCCI, P. M. et al. The varied sensitivity of partial thromboplastin and prothrombin time reagents in the demonstration of lupus-like anticoagulant. Scand J Haematol, v. 22, n. 5, p. 423-32, 1979.

27. MOORE, G.W:;SAVIDGE, G. F; SMITH, M. P. Improved detection of lupus anticoagulants by the dilute Russell's viper venom time. Blood Coagul Fibrinolysis, v. I I, n. 8, p. 767-74, 2000.

28. NAHASS, G.T.Antiphospholipid antibodies and antiphospholipid antibody syndrome. J Am Acad Dermatol, v. 36, n. 2, p. 14968, 1997.
29. NORMAN, G. R.; STREINER, D. L. Bioestatistics: the bare essentials. St.Louis: Mosby Year Book, 1994.

30. NZERUE, C. M. et al. Black swan in the kidney: renal involvement in the antiphospholipid antibody syndrome. Kidney Int, v. 62, n. 3, p. 733-44, 2002.

31. PENGO, V. et al. Immunological specificity and mechanism of action of IgG lupus anticoagulants. Blood, v. 70, n. I, p. 6976, 1987.

32. PETRI, M. et al. The frequency of lupus anticoagulant in systemic lupus erythematosus. Ann Intern Med, v. I06, n. 4, p. 524-31, 1987

33. PROVEN, A. et al. Clinical importance of positive test results for lupus anticoagulant and anticardiolipin antibodies. Mayo Clin Proc, v. 79, n. 4, p. 467-75, 2004.

34. RAUCH, J.; TANNENBAUM, M.; JANOFF, A. S. Distinguishing plasma lupus anticoagulants from antifactor antibodies using hexagonal (II) phase phospholipids. Thromb Haemost, v. 62 , n. 3, p. 892-6, 1989.

35. ROUBEY, R. A. S. Update on antiphospholipid antibodies. Curr Opin Rheumatol, v. 12, n. 5, p. 374-8, 2000.

36. STEVENSON, K. J. et al. The reliability of activated partial thromboplastin time methods and the relationship to lipid composition and ultrastructure. Thromb Haemost, v. 55, n. 2, p. 250-8, 1986.

37.THIAGARAJAN, P.; SHAPIRO, S. S.; DEMARCO, L. Monoclonal immunoglobulin M lambda coagulation inhibition with phospholipid specificity. Mechanism of a lupus anticoagulant. J Clin Invest, v. 66, n. 3, p. 397-405, 1980.

38. THIAGARAJAN, P.; PENGO, V.; SHAPIRO, S. S. The use of dilute Russell's viper venom time for the diagnosis of lupus anticoagulants. Blood, v. 68, n. 4, p. 869-74, 1986

39. TRIPLETT, D. A.; BRANDT, J. Laboratory identification of the lupus anticoagulant. Br J Haematol, v. 73, n. 2, p. 139-42, 1989.

40. VIOLI, F. et al. Lupus anticoagulant in liver cirrosis. Thromb Haemost, v. 59, n. 2, p. 335, 1988 